\title{
O bibliotecário e a competência informacional: prática profissional e aspectos curriculares
}

\author{
Greyciane Souza Lins \\ Doutoranda em Ciência da Informação. \\ greycilins@gmail.com
}

Resumo: $\mathrm{O}$ artigo apresenta resultados de uma pesquisa sobre habilidades e práticas do bibliotecário consideradas competências informacionais a serem desenvolvidas através da sua formação acadêmica. Por meio da aplicação do método Delphi, especialistas envolvidos no tema competência informacional opinaram sobre o cotidiano do bibliotecário em suas atividades e a relação com a definição de competência informacional. Conclui-se que os conteúdos ensinados devem ser formulados de forma que tópicos relacionados à competência informacional sejam adaptados e enfatizados para a prática discente e futuramente profissional.

Palavras-chave: Competência informacional, formação acadêmica, prática biblioteconômica.

Abstract: The article presents results of a survey on skills and practices of the librarian considered informational skills to be developed through professional training. Applying the Delphi method, experts involved in the issue opined about information literacy librarian in the daily activities and relationship with the definition of information literacy. We conclude that the content taught must be formulated so that topics related to information literacy are adapted to practice and emphasize student and future professional.

Key words: Information literacy; library practice.

Resumen: El documento presenta los resultados de una encuesta sobre los conocimientos y las prácticas de alfabetización en información bibliotecaria considera que se desarrollarán a través de la formación profesional. A través de la aplicación del método Delphi, los expertos involucrados en el tema opinó acerca de la bibliotecaria de alfabetización informacional en las actividades diarias y su relación con la definición de la alfabetización informacional. Llegamos a la conclusión de que el contenido que se enseña debe ser diseñada de forma que los temas relacionados con la alfabetización en información se adaptan a la práctica y hacer hincapié en los estudiantes y futuros profesionales.

Palabras claves: Alfabetización informacional; formación; Práctica bibliotecaria. 


\section{Introdução}

A abordagem do conceito de competência informacional nos currículos surgiu no final dos anos 80, assim que o termo começou a ser difundido e estudado por educadores e bibliotecários, e a partir da definição da ALA, onde "localizar, avaliar e usar efetivamente a informação" era proposta como parte da formação escolar. Nesta época, houve um maior interesse pelo assunto, surgindo a convicção de que as habilidades em informação poderiam ser ensinadas através de sua incorporação aos currículos. O bibliotecário, agora educador, inicia a prática de programas de orientação bibliográfica em vários colégios e universidades norte-americanos (BEHRENS, 1994) - atividades como programas de uso da biblioteca, ensino de estratégias de busca, métodos de solução de problemas envolvendo necessidade de informação - com o intuito de reforçar a aprendizagem em sala de aula, direcionando algumas tarefas consideradas competências em informação.

No entanto, o conceito de competência informacional passa a se ampliar no momento em que as fontes informacionais começam a se multiplicar, processo que se potencializa pelo aumento e evolução das tecnologias de informação e comunicação e bibliotecas utilizam sistemas mais modernos, incluindo sua arquitetura, sistema de pesquisa e acesso ao acervo. Pashaie (2004, p. 9) afirma que "enquanto a maioria da literatura dos anos 80 ainda enfatizava a necessidade de ensinar aos estudantes as complexas fichas catalográficas, alguns já evidenciavam a era do computador em vários artigos". Logo, o sentido de orientação bibliográfica, como era atribuído o ensino das habilidades em competência informacional por bibliotecários foi se tornando "pequeno" (BEHRENS, 1994, p. 313), quando deveria realmente ensinar as habilidades no uso da informação ao invés de habilidade no uso de bibliotecas. Por isso, o objetivo deste artigo, é investigar quais as funções que o bibliotecário exerce que podem ser consideradas competências informacionais, e como essas funções podem ser inseridas no ambiente acadêmico.

\section{Competência informacional: da teoria à sala de aula}

Nos Estados Unidos, muitas universidades adotaram o ensino de competência informacional em seus cursos, como sugerido pela Association of College \& Research Libraries . Os critérios de inclusão são baseados nas definições de competência em informação para o ensino superior e incluem as seguintes normatizações:

- A importância da adequação de recursos de informação e bibliotecas, assim como material e pessoal, para o sucesso da disciplina;

- A necessidade de instrução na prática de busca informacional;

- A necessidade para proficiência estudantil com os recursos informacionais da disciplina, ou RICl: R.Ibero-amer. Ci. Inf., ISSN 1983-5213, Brasília,v. 2, n. 1, p. 46-58, jan../jul.2009. 
- A necessidade de assegurar a todos os estudantes serem competentes em informação para o sucesso na profissão.

Além disso, a ACRL complementa os critérios curriculares, que deve se basear nos seguintes princípios:

- Clareza dos métodos de ensino de competência informacional para as disciplinas;

- Recursos aplicáveis em forma de tarefas, atividades e tutoriais direcionados para habilidades informacionais de acordo com a disciplina,

- Pesquisas que sustentem a importância da integração de tópicos de competência informacional na disciplina.

Para os estudantes de biblioteconomia, a abordagem poderia ser a mesma, mas exige algumas discussões. A literatura que aborda o tema geralmente supõe que o profissional da informação conheça os conceitos e a prática da competência informacional que podem estar implícitos em algumas disciplinas do currículo, como observado por Kajberg e Lorring (2005, p. 69) que afirma: "talvez alguns educadores tenham uma suposição de que estudantes tornemse hábeis em competência informacional por estudar biblioteconomia e ciência da informação. Mas não necessariamente". Esse fato se justifica, pois, o conceito ainda não está claramente delimitado para sua aplicação na estrutura curricular, ou o sistema educacional universitário pode ter objetivos que exijam a incorporação de outras orientações e habilidades. Algumas pesquisas brasileiras baseadas nesse contexto, afirmam que para os profissionais da informação, o conceito de competência informacional pode ainda ser desconhecido (BELLUZZO; ROSETTO, 2004 e CAMPELLO; ABREU, 2005).

Em um estudo prospectivo sobre os currículos de biblioteconomia e ciência da informação, Kajberg e Lorring (2005, p.68-69) observam a importância de pelo menos três aspectos que os estudantes da área da informação deveriam adquirir:

- Ter consciência de comportamento informacional como um conceito;

- Tornarem-se hábeis em comportamento informacional;

- Aprender alguns aspectos chave no ensino de comportamento informacional.

Essas características ajudam o profissional a manter o exercício do aprendizado ao longo da vida num ambiente onde as mudanças são inevitáveis. Segundo Kajberg (2005), ao mesmo tempo, elas os habilitam a se desenvolverem como facilitadores da aprendizagem dos usuários a se tornarem hábeis em informação. Os estudantes devem ver as características neles, antes de iniciar o ensino a alguém sobre o assunto.

Em uma pesquisa sobre características de competência informacional em alunos de graduação em biblioteconomia, Campello e Abreu afirmam: 
Para ser capaz de construir um novo paradigma e de contribuir para a educação de pessoas competentes em informação o próprio bibliotecário deve ser competente em informação e dominar as habilidades necessárias para realizar o processo de pesquisa adequadamente. (2005, p. 179).

Certamente, que nesse caso, tem-se a idéia de que a noção de ser um mediador do ensino de competência informacional deve iniciar-se na formação do profissional da informação. Mesmo com a existência de cursos de extensão, atualização e especialização em vários países, o fato reforça a idéia da inclusão da habilidade em ensinar as competências em informação para esses profissionais. Sobre o entendimento do assunto por bibliotecários, Lloyd (2005, p. 88) afirma:

Se, como bibliotecários, nós queremos ensinar competência informacional, e dar suporte à idéia de suas qualidades transformadoras e sua habilidade em capacitar, enriquecer e personificar indivíduos em suas práticas (...), então, nós precisamos nos mover além de nossos entendimentos discursivos do que é a competência informacional.

Em um estudo sobre esse tema, Karisiddappa $(2004$, p. 3) afirma que a incorporação dos conceitos de competência informacional nos currículos de biblioteconomia e ciência da informação não é uma adição especial ao ensino e treinamento, mas é interligado à estrutura, ao conteúdo e à seqüência curricular. Kajberg (op.cit.), por sua vez, afirma que o conceito pode ser pensado em uma disciplina isolada, ou talvez ser coberto implicitamente em uma ou mais disciplinas, tais como "Recuperação da Informação" ou "Gestão do Conhecimento". Em algumas Universidades norte-americanas, existem módulos que incluem o tópico em disciplinas como "biblioteca e aprendizagem" nos cursos de mestrado. O mais comum, é a abordagem do tema no curso de educação ou treinamento de usuários, enquanto outras universidades a oferecem como uma disciplina especial. Há ainda os cursos intitulados "instrução bibliográfica", "serviços instrucionais" e até "letramento na era da informação".

A oferta dos cursos que incluem o tema em seus currículos também se deve às exigências no mercado de trabalho, principalmente para bibliotecas públicas e acadêmicas (nos Estados Unidos). Mas em muitos casos existem cursos para os profissionais atuantes, que ensinam como elaborar programas em colaboração com os administradores da instituição onde a biblioteca está inserida, professores e interessados. Além disso, os programas ensinam práticas pedagógicas para planejar a lecionar sobre as habilidades em informação para os usuários. 


\section{Habilidades e práticas consideradas competência informacional}

O objetivo deste artigo é demonstrar o estudo onde são averiguadas quais habilidades do profissional da informação devem ser consideradas em algum conceito de competência informacional. Por se tratar de pesquisa envolvendo aspectos curriculares e prática do bibliotecário é necessário a opinião de professores, pesquisadores e profissionais da área para que se tenha documentado todos os argumentos que serão base para estudos futuros. $A$ técnica mais apropriada para a pesquisa foi o método delphi, caracterizada pela obtenção de previsões de uma determinada área a partir de opiniões de especialistas, onde as respostas são colhidas sem que os participantes saibam quem são os outros. A partir de suas afirmações, chega-se a um elevado número de opiniões convergentes ou mesmo ao consenso, o que pode ser conseguido através de duas ou mais rodadas de perguntas. Foram selecionados dezessete especialistas em todo o Brasil, dentre estes, quatorze respondentes. O perfil acadêmico e profissional dos consultados abrange especialização, mestrado e doutorado na área de ciência da informação. Entre as funções que desempenham em suas instituições, estão os cargos de bibliotecário, pesquisador e professor universitário.

Foram questionadas algumas características tradicionais, cuja importância seria apreciada pelos especialistas de acordo com a seguinte escala: Pouco importante Importância Média - Importante - Muito Importante, cujo o resultado pode ser visto no gráfico a seguir:

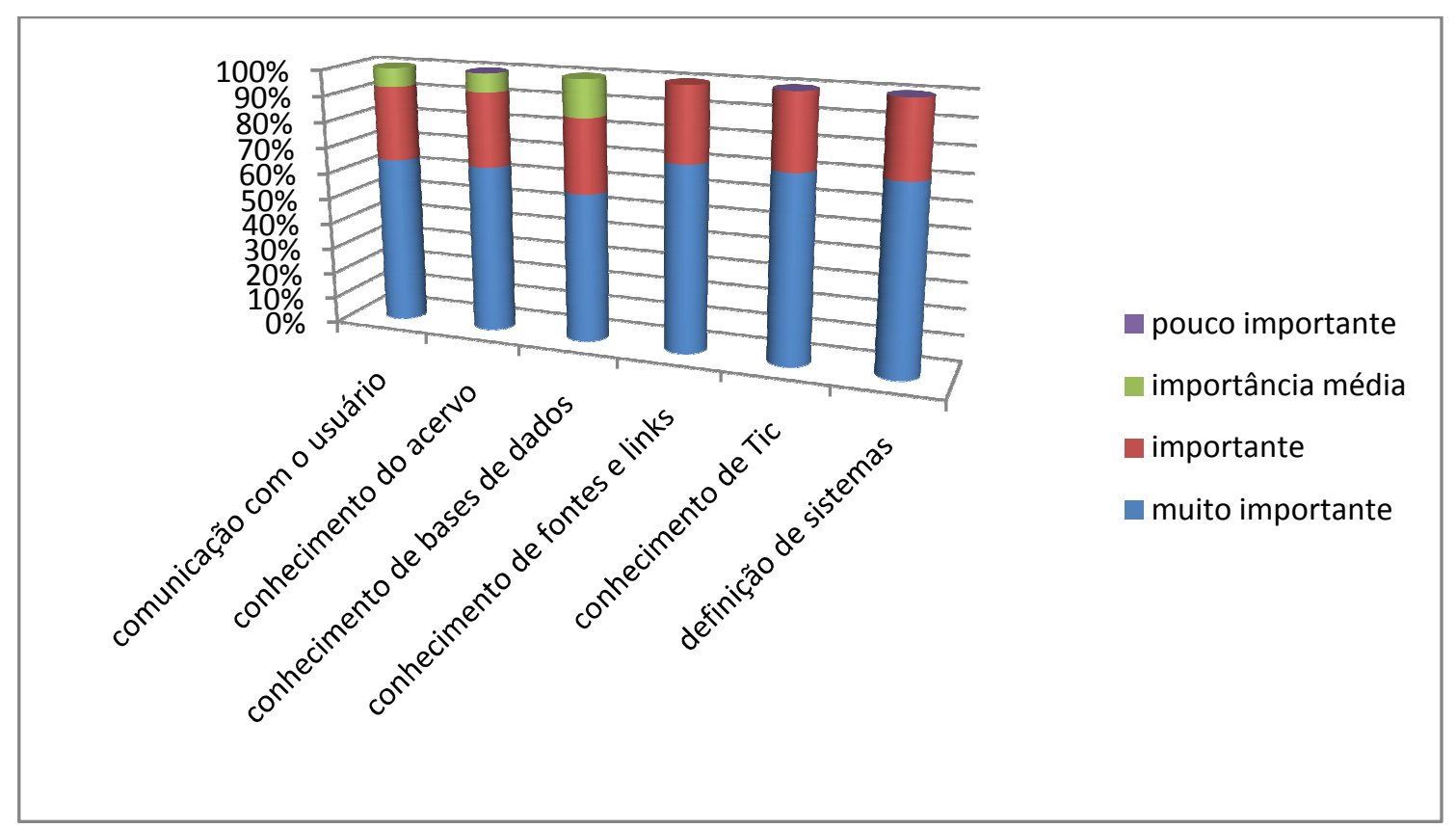


É uma das habilidades que engloba o uso da linguagem e comunicação, onde a prática se dá a partir do ensino e orientação para uso do ambiente informacional e dos recursos oferecidos. Esta função foi considerada muito importante para o conceito de competência informacional por parte da maioria dos respondentes.

b) Conhecimento do acervo

A capacidade de entendimento de diversos assuntos, ou de assuntos específicos, está incluída no conceito de conhecimento do acervo, ou seja, ter ciência de autores e tópicos específicos contidos no acervo e atualização sobre as tendências científicas nas áreas cobertas.

c) Conhecimento dos conteúdos das bases de dados

A habilidade de uso dos serviços das variadas opções de busca e o conhecimento da cobertura dos conteúdos oferecidos nas bases de dados correspondem ao tópico sobre conhecimento dos conteúdos das bases de dados da instituição. Nesta questão, doze dos quatorze respondentes consideram o conhecimento dos conteúdos das bases de dados da instituição como uma competência informacional importante ou importante para os profissionais da informação.

d) Conhecimento de fontes e links externos

O uso de diversas fontes informacionais tem o poder agregar valor e auxiliar na tomada de decisão pelo usuário. O conhecimento de diversas bases de dados, sítios na rede mundial de computadores, motores de busca, periódicos, entre outras fontes, compõem o tópico em questão. Todos os especialistas confirmam que tal habilidade é característica da competência informacional dos profissionais da informação, variando de importante para muito importante.

e) Conhecimento das tecnologias da informação e da comunicação

Saber utilizar e conhecer a tecnologia para recuperar a informação necessária é uma das mais importantes habilidades em competência informacional. Embora pareça tarefa comum, essa habilidade exige um grau de conhecimento apurado e especifico, principalmente quando se trata do profissional da informação. Isso significa que a habilidade no uso das tecnologias da informação e comunicação por parte desses profissionais certamente devem compor um grau diferenciado devido ao método.

f) Competência para definir as características e qualidades de novos sistemas interativos da instituição e comunicá-las aos responsáveis pelo seu desenvolvimento e implementação (programadores, webmasters, etc.)

A produção de sistemas e programas adequados na instituição, quando realizada em parceria entre os profissionais da informação e os responsáveis técnicos podem ter maior RICl: R.Ibero-amer. Ci. Inf., ISSN 1983-5213, Brasília,v. 2, n. 1, p. 46-58, jan../jul.2009. 
eficiência e sucesso quanto ao seu uso. A competência em questão abrange a capacidade de interação e comunicação por parte do profissional da informação em relacionar seus conhecimentos sobre organização e recuperação da informação, metadados, perfil do usuário, linguagens de indexação, etc. para a criação de sistemas interativos da instituição. A maioria dos especialistas afirmou que a habilidade para definir as características e qualidades de sistemas interativos é considerada muito importante enquanto competência informacional.

Como questão aberta, foi solicitada aos especialistas a indicação de outras características profissionais consideradas como competência informacional:

- $\quad$ Competência para avaliar a fonte de informação consultada

- $\quad$ Competência para fazer análise e síntese da informação

- Conhecimento de como é estabelecida a comunicação científica da área de atuação do profissional (no caso de informação técnico/científica)

- Educação para competência informacional

- $\quad$ Conhecimento em inovações em gerenciamento de bibliotecas

- Interesse em contribuir socialmente com a mediação da leitura e pesquisas

- Entendimento do cenário social e suas transformações sob o enfoque tecnológico e informacional

- As novas condutas de gestão da informação e do conhecimento,

- Metodologia da pesquisa e gestão de projetos investigativos

A partir dessa relação, pode-se constatar que algumas práticas profissionais podem ser aprofundadas segundo o conceito de competência informacional, já ensinadas no curso de graduação, seja dentro das matérias, seja em cursos de extensão e com a experiência profissional.

\section{Aspectos curriculares em Biblioteconomia}

Nesta parte da pesquisa, o objetivo da questão foi a coleta de opiniões a respeito da necessidade de inclusão, e em caso positivo, como poderia se incluída. Para essa pergunta, a resposta deveria ser positiva ou negativa para atribuição das respostas, além da questão aberta.

O primeiro tópico teve a questão "Você considera de interesse incluir o tema competência informacional nos currículos?". Todos os respondentes consideraram que a inclusão é necessária, o que confirma a tendência mundial no ensino de biblioteconomia e ciência da informação. Segundo o relatório final do "Workshop Competência em Informação (information literacy)," coordenado pela professora Regina Célia Batista Belluzzo (2005), uma 
das recomendações propostas é de que "os órgãos competentes possam sugerir a inclusão do tema competência em informação e de outros ligados à educação no currículo dos cursos de biblioteconomia e ciência da informação". Portanto, a unanimidade de respostas afirmativas contribui de forma importante para a reflexão e direcionamento deste tópico. O segundo tópico questionou sobre a possibilidade de incluir o tema em uma disciplina isolada. Dos quatorze respondentes, três afirmaram que sim, a competência informacional pode ser ensinada em uma única disciplina, e sugeriram as ementas, listadas abaixo:

- Introdução ao estudo da Competência Informacional e da informação.

- O ciclo da comunicação e da informação na Sociedade da Informação. Competência Informacional: conceituação, objetivos e funções.

- $\quad$ As teorias educacionais construtivistas.

- $\quad$ O bibliotecário e a socialização do conhecimento.

- Análise da Competência Informacional dentro de instituições públicas e privadas no contexto regional e nacional.

- Uso das tecnologias e métodos relacionados com a informática aplicada aos processos documentários.

- Unidades e serviços de informação.

- $\quad$ Elaboração, implantação e participação em projetos de sistemas de informação.

- Informação e seus aspectos filosóficos e epistemológicos.

- $\quad$ Comunicação digital.

- A função e a característica da informação na sociedade atual.

- A competência informacional e seus processos de busca, construção, análise e divulgação.

- O significado da informação no processo da educação formal.

- As tecnologias como mediadoras e potencializadoras do processo de competência informacional.

- Competência informacional: conceitos, origem, evolução.

- $\quad$ Competência informacional, leitura e letramento.

- $\quad$ Aprendizagem por meio de busca e uso da informação.

- Competência informacional: programas para o desenvolvimento de habilidades informacionais.

Como conteúdo distribuído nas disciplinas, a maioria afirmou que a forma de inclusão poderia se dar dessa maneira: 


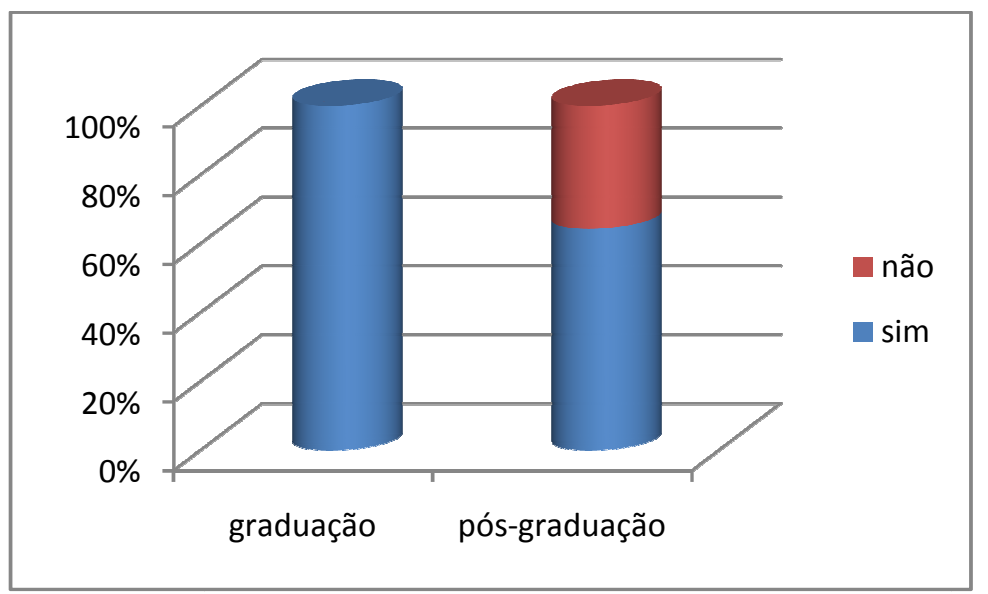

Disciplinas que podem incluir o tema

Esta parte da pesquisa contém uma lista de disciplinas sugeridas, as quais foram julgadas se deveriam ou não, e em que medida, contemplar algum conteúdo de competência informacional. O objetivo desse questionamento é averiguar quais disciplinas poderiam incluir em seu plano de ensino, aspectos do tema competência informacional. Os especialistas deveriam responder sobre cada item, sim ou não, e caso a resposta fosse afirmativa, classificariam de acordo com a seguinte escala de valores: Pouco importante - Importância Média - Importante - Muito Importante.

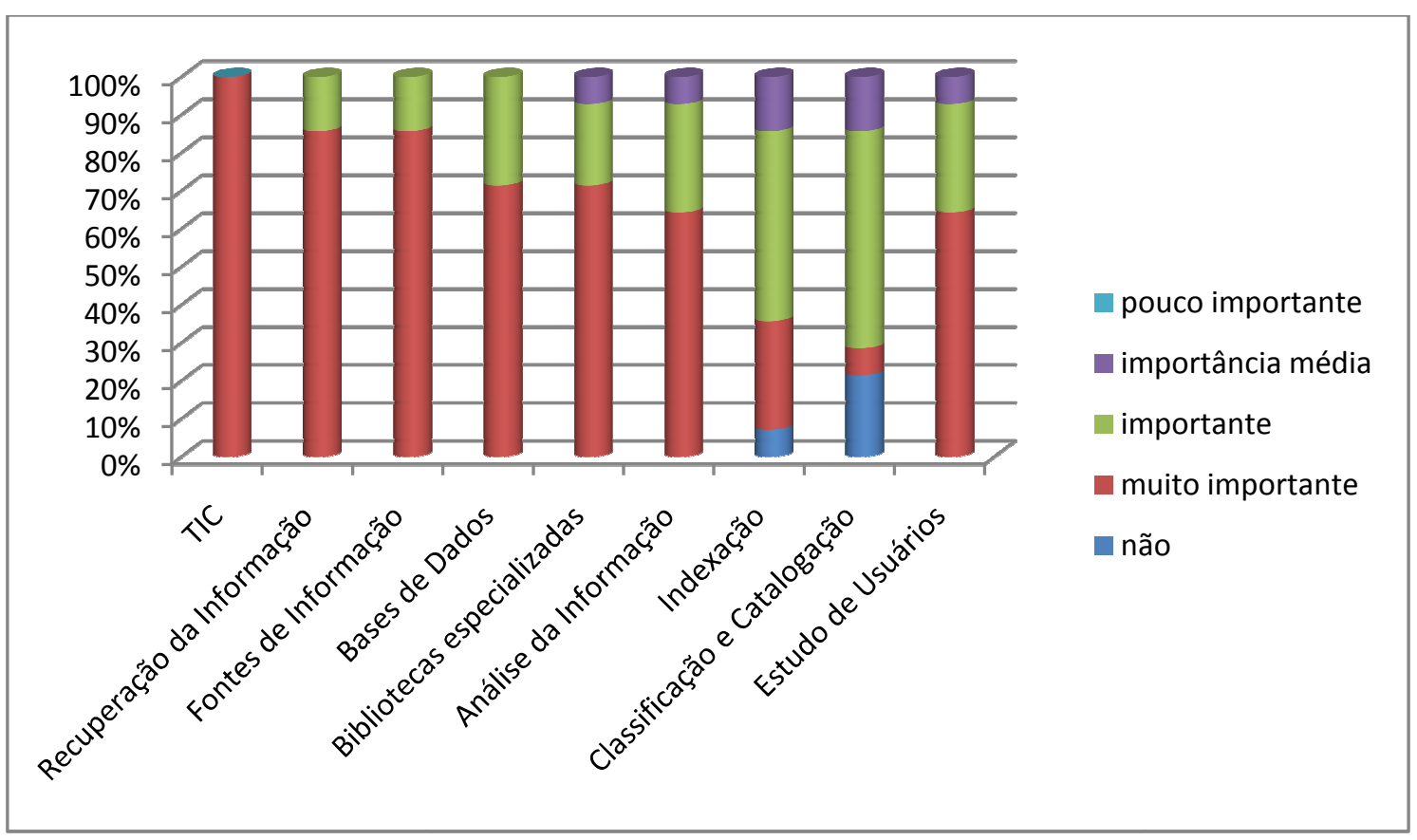


Como observado no gráfico, as disciplinas de organização da informação são as que menos estão associadas com o tema competência informacional, enquanto as que focalizam a tecnologia e os serviços de informação são a maioria em nível de importância para a inclusão do tema competência informacional em seu plano de ensino. Essa análise confirma que a competência informacional deve ser ensinada também sob uma visão mais moderna dos conceitos de tecnologia da informação e comunicação.

\section{Considerações finais}

O cotidiano do bibliotecário pode ter variações de acordo com a sua especialidade, seus usuários e cultura institucional, portanto é necessário entender onde o conceito de competência informacional está inserido na sua prática profissional específica. A própria definição de competência informacional tem aplicações para diferentes públicos (infantil, adolescentes, pós-graduandos, etc) e o bibliotecário deve entender como a competência informacional pode ser adaptada à sua realidade. Esta pesquisa demonstrou que muitas tarefas executadas podem ser consideradas habilidades em competência informacional, mas não significa afirmar que o bibliotecário é competente em informação, pois não foi considerada a eficiência e efetividade com que as atividades são executadas e as finalidades de cada uma. Portanto, sugeriu-se a segunda fase da pesquisa, onde se questionou a inserção de assuntos ligados ao tema nos planos de ensino para a formação do bibliotecário, pois mesmo que o profissional seja um sujeito competente em informação pela sua formação, como pode ser argumentado, ele precisa disseminar as habilidades informacionais com o objetivo de formar usuários capacitados para o uso da informação e conscientes da importância da informação.

Como observado, os resultados da pesquisa mostraram que as disciplinas ministradas nos cursos de graduação devem considerar os aspectos de competência informacional, algumas em maior, outras em menor grau, de forma que conceitos, modelos, projetos e a prática do tema possam ser incluídos e adaptados aos planos de ensino. Isso com o objetivo de que a atuação dos profissionais da informação seja de acordo com a teoria e a prática adquirida durante sua formação, ou seja, que eles sejam competentes em informação a partir dos métodos acadêmicos, os quais devem refletir as características que exigem um posicionamento voltado para o ensino de competência informacional pelos profissionais.

Portanto, sugere-se que o currículo e as ementas sejam revistos, e discutidos com especialistas, e reformulados, para adaptar a formação acadêmica ao mercado de trabalho e principalmente a realidade social, visando questões educativas. 
A expansão da divulgação e a prática da competência informacional podem ser consideradas como medida preventiva e educativa para a população, com o intuito de solucionar diversos problemas sociais, e essa proposta pode ser auxiliada pelo profissional bibliotecário.

\section{REFERÊNCIAS}

ALA. American Library Association. The information literacy competency standards for higher education. Chicago: Association of College and Research Libraries, 2000.

BEHRENS, Shirley J. A conceptual analysis and historical overview of information literacy. College and Research Libraries, p. 310-323, July 1994.

BELLUZZO, Regina Célia. Relatório do Workshop Competência em Informação (information literacy). Disponível em: <www.febab.org.br. Acesso em 2 jun. 2007.

; ROSETTO, Marcia. O estado da arte da visão e valores da competência em informação (information literacy) na sociedade contemporânea e as necessidades de capacitação dos profissionais da informação: um cenário das bibliotecas universitárias estaduais paulistas.. In: SEMINARIO NACIONAL DE BIBLIOTECAS UNIVERSITARIAS, SNBU, 14., 22-27 out. 2006, Salvador, Bahia. Anais do XIV SNBU. Salvador: UFBA, 2006.

CAMPELLO, Bernadete; ABREU, Vera Lúcia Furst Gonçalves. Competência informacional e formação do bibliotecário. Perspectiva em Ciência da Informação, Belo Horizonte, v. 10, n. 2, p. 178-193, jul. 2005

KAJBERG, L; LORRING, L. European curriculum reflection on library and information science. Copenhagen: The royal school of library and information science, 2005.

Karisiddappa, C.R.; PORS, Niels Ole; WESH, Terry L. Literacy concepts in the LIS curriculum. In: WORLD LIBRARY AND INFORMATION CONGRESS: IFLA GENERAL CONFERENCE AN COUNCIL, 70., 2004, Argentina. Papers, IFLA, 2004.

LLOYD, Annemaree. Information literacy: different contexts, different concepts, different truths? Journal of Librarianship and Information Science, 37, 2, p. 82- 88, june 2005.

LINS, G.S. Inclusão do tema competência informacional e os aspectos tecnológicos relacionados, nos currículos de biblioteconomia e ciência da informação. Brasília, 2007. 103 f. Dissertação (Mestrado em Ciência da Informação) - Programa de Pós-Graduação em Ciência da Informação, Universidade de Brasília.

PASHAIE, Billy. A history of information literacy in community colleges as represented by articles in the professional press. Final Assignment, Information Studies, 281. UCLA, June 2004. 